\title{
Idea del espacio escénico y lugares para la representación teatral entre los siglos XV y XVI. Modelos de teatro a la manera de Italia
}

\author{
Tiziana Mazzucato \\ Universidad Nacional Experimental de las Artes, Venezuela \\ tmazzucato@gmail.com
}

Fecha de recepción: 10/09/2009. Fecha de publicación: 23/12/2009

http://www.studiaaurea.com/articulo.php?id=113

\begin{abstract}
Resumen
El edificio teatral que hoy conocemos tuvo su origen y más rápido desarrollo en un período de cien años, comprendidos entre los siglos xv y xvi. Suele atribuirse esa consolidación del espacio escénico a la relectura que los teóricos quinientistas hicieron del De architectura de Vitruvio y de las fuentes arqueológicas que describían los teatros griegos y, especialmente, los romanos. La reconstrucción por arqueología textual del teatro antiguo favoreció la forma de conceptualizar el teatro moderno: las partes de su estructura y la descripción del escenario son reinterpretaciones del canon vitruviano, y varios de los elementos arquitectónicos fundamentales, como el arco-escénico, los balcones del auditorio y la forma de disponer la sala y el escenario, resultaron de un complejo proceso de reelaboración que conjugó las formas antiguas con las prácticas modernas. Entre las aportaciones más relevantes de los arquitectos quinientistas se cuentan las nuevas reglas de la perspectiva aplicada a la escenografía y los sistemas de iluminación de todo el aparato teatral. Gracias al perfeccionamiento de la ilusión óptica y a la distribución y control de la intensidad de la luz se potenciaron los artificios escénicos y se legitimaron, de este modo, las nociones de deleite y maravilla que dominarían durante mucho tiempo el concepto de teatro. Ha de señalarse, no obstante, que hasta 1540 no existían edificios especialmente destinados al teatro y que las representaciones solían realizarse en estructuras provisionales encajonadas en los salones y los patios de los palacios reales. La práctica de construir teatros efímeros también condicionó la distribución de los teatros estables que prevalecieron en Europa hasta finales del siglo xIx, y cuyas tipologías aún son reconocibles en la mayor parte de los teatros del occidente latino.
\end{abstract}

Palabras clave

Vitruvio, teoría del teatro, teoría de la puesta en escena, escenografía, perspectiva, teatros efímeros, teatros estables, Sebastiano Serlio, Andrea Palladio, Teatro Olimpico de Vicenza 


\begin{abstract}
Idea of the stages and places for the performing arts from the 15th to the 16th century. Theatre models in the "Italian style»

The theatrical building that we know nowadays was originated and developed rapidly in a hundred year period, between the 15th and 16th century. The consolidation of the scenic space is usually attributed to the review the sixteenth-century theorist of Vitruvius's De Architectura and archaeological sources that described Greek and Roman theaters specially. The reconstruction through textual archeology of the ancient theater served to conceptualize modern theater: parts of its structure and the description of the stage are reinterpretations of the vitruvian cannon and many of the architectural elements are fundamental such as the proscenium arch, the auditorium balconies and the arrangement of the proscenium and the stage. All these resulted from a complex reelaboration process that conjugated ancient forms with modern practices. Among the most important contributions of the sixteenth-century architects, are the new lineaments of perspective applied to the scenery and the lighting systems of the theatrical apparatus. Scenic devices were enhanced and legitimized by the perfectionism of optical illusion and the distribution and control of lighting intensity. For a long time, this gave the theater concept notions of delight and wonder. We must note that until 1540 there were no special buildings destined for theaters and representations took place in provisional structures that were constraint in royal halls and courtyards. The practice of building ephemeral theaters also conditioned the location of stable theaters that prevailed in Europe until the end of the 19th century and whose typologies are still recognizable in the majority of theaters of the Latin west.
\end{abstract}

Key words

Vitruvius, theatre, scene theory, scene, perspective, scenografy, stable theatres, ephemeral tetares, Sebastian Serlius, Andrea Palladio, Olympic Theatre of Vicenza.

El edificio teatral que hoy conocemos tuvo su origen y más rápido desarrollo en un período de cien años, comprendidos entre los siglos Xv y xvI. Suele atribuirse la consolidación del espacio escénico a la relectura que los teóricos quinientistas hicieron del De architectura de Vitruvio y de las fuentes arqueológicas que describían los teatros griegos y, especialmente, los romanos. La reconstrucción por arqueología textual del teatro antiguo favoreció la forma de conceptualizar el teatro moderno: las partes de su estructura y la descripción del escenario son reinterpretaciones del canon vitruviano, y varios de los elementos arquitectónicos fundamentales, como el arco-escénico, los balcones del auditorio y la forma de disponer la sala y el escenario, resultaron de un complejo proceso de reelaboración que conjugó las formas antiguas con las prácticas modernas. Entre las aportaciones más relevantes de los arquitectos quinientistas se cuentan las nuevas reglas de la perspectiva aplicada a la escenografía y los sistemas de iluminación de todo el 
aparato teatral. Gracias al perfeccionamiento de la ilusión óptica y a la distribución y control de la intensidad de la luz se potenciaron los artificios escénicos y se legitimaron, de este modo, las nociones de deleite y maravilla que dominarían durante mucho tiempo el concepto de teatro. Ha de señalarse, no obstante, que hasta 1540 no existían edificios especialmente destinados al teatro y que las representaciones solían realizarse en estructuras provisionales encajonadas en los salones y los patios de los palacios reales. La práctica de construir teatros efímeros también condicionó la distribución de los teatros estables que prevalecieron en Europa hasta finales del siglo XIX, y cuyas tipologías aún son reconocibles en la mayor parte de los teatros del occidente latino.

En las páginas que siguen quisiera abordar la cuestión del espacio escénico en el Renacimiento mediante el estudio de las dos vertientes que contribuyeron a su materialización: la filológica, que proviene de los comentarios a los libros de Vitruvio y de la escritura de los primeros tratados quinientistas sobre perspectiva aplicada a la decoración de los escenarios, y la arquitectónica, que resultó de la práctica de improvisar estructuras teatrales en espacios concebidos para otros fines. Concluiré esta revisión sumaria con la descripción del teatro renacentista más antiguo que se conserva, el Olímpico de Vicenza de Andrea Palladio. El modelo palladiano es especialmente importante porque revela los intereses de la teoría arquitectónica y de la práctica teatral del siglo xvi. Varios de sus elementos han permitido, además, completar la imagen de otros escenarios hoy perdidos, y, con ello, reconstruir un momento capital de la historia del teatro y de las representaciones escénicas. ${ }^{1}$

1. Este artículo forma parte de una investigación mayor sobre la influencia del arte y la arquitectura humanistas en la concepción del espacio escénico moderno, que realizo en el Seminario de Poética del Renacimiento de la Universidad Autónoma de Barcelona. 


\section{La lectura de Vitruvio}

El proceso de interpretación de la arquitectura antigua fue lento y paulatino y requirió el concurso de artistas, arquitectos y críticos. La indagación historiográfica que intentó restituir esa imagen de la escena mediante bocetos, documentos y ruinas fue profusa, pero tuvo, en realidad, una incidencia menor que la de la exégesis de los tratados teóricos, que terminó por constituir el verdadero cimiento del nuevo edificio teatral. Las lecturas, traducciones y comentarios de los críticos renacentistas favorecieron la decantación de una imagen, hasta entonces confusa, del teatro llamado a la italiana. ${ }^{2}$

En general, la corriente crítica proviene del único tratado del género que pervivió de la antigüedad, los Diez libros de arquitectura de Vitruvio, cuya princeps es de 1486, aunque su contenido había sido ampliamente difundido en manuscritos desde 1414. De Vitruvio proceden las noticias y las normas que introdujeron en la terminología corriente la nomenclatura latina. Aun así, en este tratado las noticias sobre la puesta en escena son pocas y (a falta de esquemas o gráficos) de difícil comprensión. Vitruvio había dedicado algunos capítulos del libro quinto a la construcción de edificios que alojan espectáculos: establece en ellos que el largo de la escena teatral es directamente proporcional al doble del diámetro de la orquesta (el púlpito constituye la duodécima parte, mientras que la altura de las columnas del fondo debe ser un cuarto del diámetro de la orquesta). Afirma Vitruvio que la pared del escenario

2. Varias obras del Renacimiento se encargan de establecer las características del teatro antiguo con bases arqueológicas: se trata de estudios que se apoyan en el cotejo entre las ruinas y las fuentes clásicas y la epigrafía. Tal es el caso de la Descriptio Urbis Romae (1432-1434), de Leon Battista Alberti, que, aunque no se dedica al teatro, se erige como un modelo dentro del género; o de la Roma Instaurata (14441446), de Flavio Biondo, cuyo libro segundo está dedicado a los orígenes y características del teatro, y que recoge entre sus fuentes principales a Plinio y su fastuosa descripción del teatro de Scauro; los cuatro libros de Poggio Bracciolini, De Varietate Fortunae (1448), pasan revista al estado en que se encontraban los monumentos desenterrados en la Roma de $\mathrm{Ni}$ colás V: el Coliseo, el Teatro Marcello, el Circo Máximo y el Teatro de Pompeyo. Della Belleza e anticaglia di Roma (1457), de Giovanni Rucellai, contiene una descripción de la forma y la función del Coliseo, así como del Teatro Marcello y del Circo de Gaio y Nerón. Unos años más tarde, Bernardo Rucellai, pariente de Giovanni, escribe De urbe Roma. Una obra novedosa de Pomponio Leto, Excepta a Pomponio dum inter ambulandum cuidam bomino ultramontano reliquias ac ruinas urbis ostenderet, narra una visita guiada por Pomponio a un extranjero entre las ruinas de Roma. Además de las descripciones de los principales teatros, el texto inaugura una tradición de relatos de visitas guiadas. Sólo a mediados del siglo XVI, en 1553, escribió Pirro Ligorio el primer tratado arqueológico ilustrado sobre circos, teatros y anfiteatros: Delle antichità di Roma, nel qual si tratta de i circi, theatri, et anphitheatri d'essa città, en el que lleva a cabo una relación de todos los monumentos teatrales de Roma, de los cuales da sus características y localización exacta. Al igual que Biondo y muchos humanistas del Cuatrocientos, Ligorio describe las tres escenas del teatro Scauro como hechas de mármol, cristal, marfil y oro. Es el primero en hacer alusión a las naumaquias. Vid. González (2001:23-43) y Cruciani (1987). 
está constituida por tres zonas sobrepuestas, y que esa frons scenae debe dividirse en cinco o siete sectores, en cuyos espacios se colocarán los periactos, unos prismas triangulares capaces de girar sobre sí mismos por medio de un perno: cada una de las tres caras del prisma soporta un bastidor ilustrado con la imagen requerida para cada tipo de escenografía. El escenario propiamente dicho, que se define en muy pocas líneas, se describe de acuerdo con el género de la obra que hubiera de representarse, y distingue para ello el trágico, del cómico y del satírico. El primero tiene columnas, frontón e insignias reales; el segundo ofrece a la vista un conjunto de edificios; el tercero, espeluncas, montes y árboles.

De Vitruvio proceden también, en otro orden de requerimientos, el modo de exponer la estructura y la función del edificio del teatro. En un apretado resumen: 1) La edificación tiene por finalidad acoger al pueblo que se reúne para la celebración de sus fiestas, y éste ha de agruparse y distribuirse de acuerdo con un estricto criterio jerárquico. Para lograr una distribución del público ordenada y efectiva, hay que disponer varias puertas de acceso, así como rampas que le dirijan directamente a las gradas correspondientes. El diseño de la planta teatral se hace en función de esa deseable fluidez de los movimientos del público. 2) La representación no es un hecho sustancial, sino más bien oratorio. Lo importante para el arquitecto es lograr una perfecta difusión de la voz; por ello, los teatros griegos estaban emplazados en el borde de una colina y la cavea reposaba sobre el pie de la montaña y tenía forma de semicírculo. El anfiteatro romano lograba un efecto similar al completar el semicírculo, pues imita la forma radial en que se expanden las ondas. ${ }^{3}$

3. La primera edición del De architectura de Vitruvio (1486) estuvo a cargo de Sulpizio Da Veroli; Fra Giocondo Giovanni da Verona reeditó el tratado latino en 1511 e incluyó 140 xilografías, entre las que se cuentan las plantas de los teatros griego y romano; en 1514, Fabio Calvo realiza la primera traducción al vulgar del texto latino y le encarga a Rafael Sanzio la realización de las ilustraciones. Aunque esa edición no fue publicada, Rafael difundió sus propuestas a través de los diseños de las escenografías y del teatro romano que proyectó para el interior de la Villa Madama. En 1521 se edita la traducción vulgar y el comentario de Cesare Cesariano al De architectura de Vitruvio, que incluye ilustraciones de su propia mano. El teatro de Cesariano nace - como los anteriores - de la interpretación del texto latino; sin embargo, los elementos que dispone para el edificio teatral parecen proceder de la imagen del Coliseo, fundida con la de los Mirabilia Urbis Romae. Del texto de Cesariano deriva la edición de Giambattista Caporali, en 1536, que retoma parte de la esquematización del teatro de Cesariano y un buen número de sus ilustraciones. Un miembro de la academia vitruviana constituida en Roma, Guillaume Philander, realizó un estudio filológico del $D e$ architetura en 1544, por encargo de Francisco I. El texto es muy valioso porque describe los prismas triangulares que reseńa Vitruvio en su tratado, la scena mutabile, y explica otro «método" antiguo para cambiar las escenas, como la scena ductilis, que consistía en retirar una escena para dejar ver una segunda que estaba oculta detrás de la primera. Las últimas dos ediciones italianas del siglo corresponden a Battista da Sangallo (hacia 1540) y a Daniele Barbaro (en 1556). Sangallo traduce el texto, comenta cada ilustración y ofrece su interpretación de los tres tipos de escena que dibuja en perspectiva. Barbaro también traduce y comenta a Vitruvio, pero su texto trasciende los anteriores por dos razones: 
La primera lectura crítica de los preceptos vitruvianos la hace Leon Batista Alberti, entre 1443 y 1452, y está recogida en su tratado de De re aedificatoria, publicado póstumo en 1485. El teatro que propone Alberti en el Cuarto Libro consta de una escalinata (la cavea) rematada por una logia (una galería abierta al frente y cerrada atrás), con un escenario y un área mediana (la orquesta), que fue reducida de un círculo (como proponía Vitruvio) a un semicírculo. ${ }^{4}$ El área

por hacer su exposición de forma sistemática y coherente, y con un método basado en los principios aristotélicos, pitagóricos y euclídeos, y por contar con las ilustraciones de Andrea Palladio. Vid. González (2001: 87-122) y Molinari (1972: 431-449).

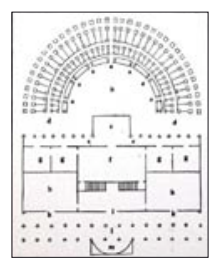

a

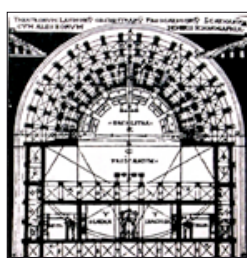

$\mathrm{b}$

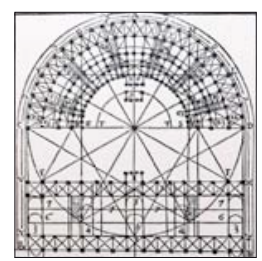

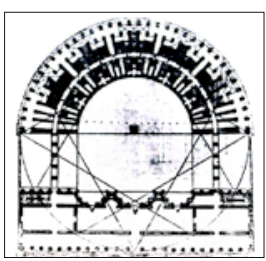

d

Figura 1

De izquierda a derecha: a) Planta del teatro griego de la edición de Fra Giocondo al De architectura de Vitruvio, 1511. b) Planta del teatro romano de la edición de Cesare Cesariano al De architectura de Vitruvio, 1521.

c) Planta del teatro romano de la edición de B attista Caporali al De architectura de Vitruvio, 1536. d) Planta del teatro romano, ilustración de Andrea Palladio a la edición del De architectura de Vitruvio de Daniele Barbaro, 1556.
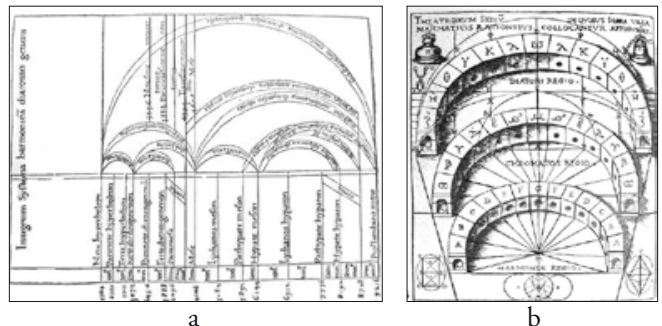

Figura 2

Cesare Cesariano, a) Tabla del sistema de la armonía y

b) Esquema de resonancia acústica del auditorio, ilustraciones al De architectura de Vitruvio, 1521.

4. Sucesivamente, y a partir de la propuesta de Alberti, Giocondo, Cesariano y Bárbaro inscriben los cuatro triángulos que determinan toda la planta del edificio teatral diseñada por Vitruvio, no en la orquesta — donde originalmente estaban emplazados - sino en el perímetro mismo del teatro. Con ello, van desplazando y, literalmente, reduciendo el escenario. A los errores interpretativos se suma, por otra parte, el hecho de que Vitruvio dedicó a la escena sólo unos breves pasajes. Molinari (1971:31-32). 


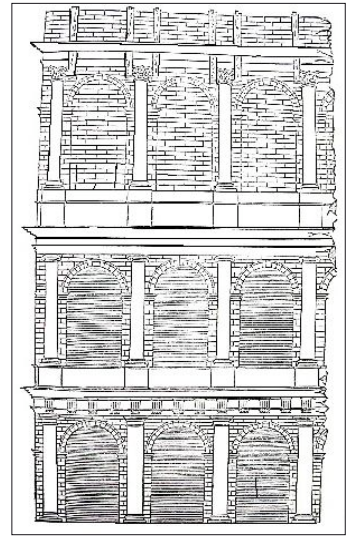

a

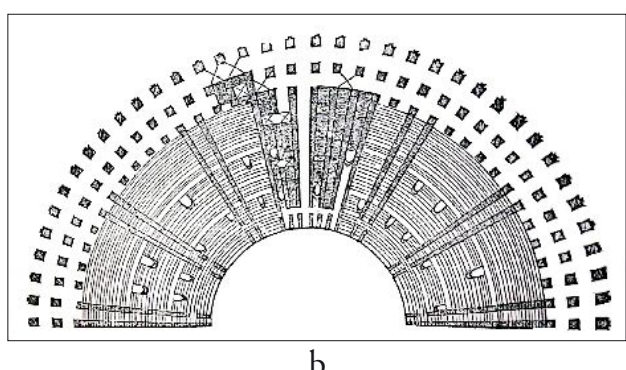

Figura 3

Leon Battista Alberti, a) Alzado de la logia y b) planta de la cávea,

De re aedificatoria, 1485 .

mediana funge como el epicentro de todo el edificio teatral: sus dimensiones son la guía que determina la proporción y la ubicación del resto de los elementos. Al igual que los teatros romanos tiene forma semicircular, pero sus extremos se retraen con dos líneas paralelas, entre las cuales se disponen el escenario y el edificio escénico, o fronscenae según Vitruvio, para rematar la arquitectura interna del teatro y servir de fachada para la escenografía. Alberti recomienda la ubicación delante del edificio escénico de dos o más columnatas de forma tal que asemejen casas: sintetiza así la escena arquitectónica clásica, de la que se conserva la puerta regia, decorada como los templos, y la necesidad de dar a la representación teatral una apariencia más real y funcional, porque esas casas debían representar las moradas de los protagonistas. Distingue asimismo la escena de los géneros trágico y satírico; para éste último contempla un fondo con árboles y montes, y otras partes agrestes similares. ${ }^{5}$

Alberti inauguró una tradición, a mitad de camino entre la interpretación anticuariay la propuesta innovadora, que calaría hondo entre sus contemporáneos. Los traductores de Vitruvio, que ya habían incorporado sus comentarios, comenzaron también a reflexionar y observar las nuevas posibilidades del espacio escénico. Ejemplo de esta reelaboración es el tratado de Pellegrino Prisciano, un humanista al servicio de la corte de los Este, que a finales del siglo $\mathrm{XV}$ organizó y representó en Ferrara comedias romanas. ${ }^{6}$ El tratado de Prisciano tiene por título Spectacula, y además de incluir una detallada interpretación del De re aedificatoria de Alberti y de algunos fragmentos de Vitruvio, contiene tres

5. Molinari (1972:112-116).

6. Ferrari (1982) y Tafuri (1987). 
nuevas recomendaciones sobre el espacio teatral: (1) considera plausible incluir entre los lugares de la ciudad adecuados para hacer espectáculos el foro, la logia, los pórticos y las columnatas - y no sólo el teatro, el anfiteatro y el circo(2) describe un teatro con "forma de luna decreciente», entre cuyas partes - el área mediana, las gradas que la rodean y los pórticos superior y externo- destaca la que llama un exagerato pulpito, un espacio que Prisciano pone en lugar de la orquesta y que está dotada de una tribuna elevada y destinada al público privilegiado. Sus consideraciones no provienen sólo de la exégesis de los estudios arquitectónicos, sino de la praxis adquirida en el oficio del montaje. Tal vez por ello escribe entre las acotaciones que para la escenografía de las comedias podrían erigirse «edificios privados y civiles, con ventanas y puertas, a imagen de los edificios comunes». Es ésta una reelaboración de la idea albertiana de construir una escena urbana con casas, pero Prisciano sugiere además que deben asemejarse a las de la ciudad donde se desarrolla la fábula. (3) Por último, retoma la idea antigua de las máquinas para el cambio de escenario (scena mutabile), los prismas triangulares que Vitruvio llamaba periaktoi.

... Y por tal disimilitud entre las escenas, con gran ingenio aquellos antiguos arquitectos usaban una máquina versátil que continuamente cambiaba la forma y la fachada del escenario, y que a placer rápidamente mostraba palacios de señores, casas de ciudadanos, selvas, así como lo dictaba la necesidad y lo exigía el propósito de las fábulas. ${ }^{7}$

7. Aguzzi Barbagli (1992). También Molinari (1972:140), Cruciani e Seragnoli (1987:56) y Mariotti (1973:53-76) En esta última edición se recogen la mayoría de los tratados (íntegra o parcialmente) concernientes al teatro y la puesta en escena del Renacimiento italiano, así como de las ilustraciones que los acompañan. 


\section{La escena en perspectiva}

En 1545 se publicó en París el «Tratado sobre los escenarios» de Sebastiano Serlio, incluido en El segundo libro (Libro II, Di prospettiva), que forma parte de un conjunto mayor de tratados que fueron editados en un solo volumen en 1584, en Venecia, bajo el tít ulo Los siete libros de arquitectura. Por su discurso sistemático y su lenguaje llano, Serlio divulgó las principales noticias teóricas y prácticas del teatro humanístico, y contribuyó de modo decisivo a su difusión más allá de Italia. Interesan especialmente los tres tratados contenidos en el libro sobre los escenarios, porque describen la aplicación de la perspectiva a los planos y a los volúmenes («Tratado de perspectiva de las superficies» y «Tratado de perspectiva de los cuerpos»), y el último por estar especialmente dedicado al teatro.

Puesto que el sutil arte de la perspectiva es muy difícil de [d]escribir, y sobre todo aquél de los cuerpos relativos al plano (...) diré bien que la perspectiva es lo que Vitruvio denominó escenografía, es decir, el frente y los lados de un edificio, y también de cualquier cosa, superficie o cuerpo. ${ }^{8}$

El Libro II comienza con una consideración general sobre el teatro. Serlio dedica importantes elogios a las cosas que se representan en escena por los efectos emocionales que suscitan en la audiencia: «resultan tan agradables al ojo y al espíritu, que ninguna otra de tipo material, realizada por el arte, se podría imaginar más hermosa». ${ }^{9}$ Se ocupa luego de explicar las leyes de la perspectiva aplicada a los planos, y especialmente ideadas para la ilustración de las escenas teatrales. Bajo los lineamientos vitruvianos, Serlio fija de modo definitivo la tipología de las tres escenas, la cómica, la trágica y la satírica, que ejemplifica a través de ilustraciones y de una serie de sugerencias técnicas para su ejecución. Establece para la escena cómica edificios representativos de las personas comunes, «los ciudadanos, los abogados, los mercaderes parásitos y otras personas similares", por lo que no deben faltar la casa de la alcahueta, la hostería y un templo. Para la trágica, dispone casas de señores, duques y grandes príncipes, y concibe, en fin, la escena satírica como un paisaje agreste con algunas cabañas, que considera habitación propia de la gente rústica.

Con miras más típicamente arquitectónicas, el tratado del Serlio incluye aspectos de la puesta en escena y confiere al aparato una finalidad representativa. Ofrece importantes indicaciones sobre la tipología arquitectónica del teatro, delinea su esqueleto y dispone sus elementos. Dibuja una planta y un corte transversal, probablemente a imitación del teatro que había proyectado y

8. Il secondo libro di Perspettiva, Marotti.

9. Idem, Sambricio (1986: 259)(1974:190-205) y Sambricio (1986). 


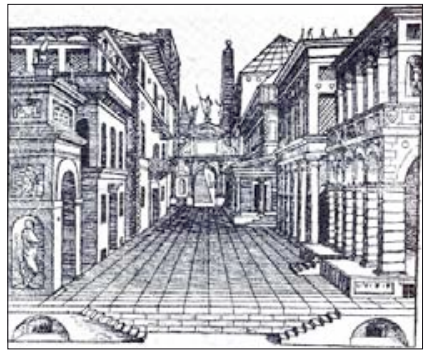

a

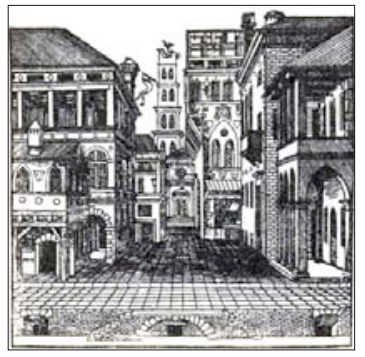

b

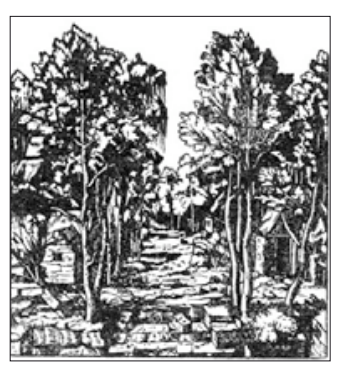

$\mathrm{C}$

Figura 4

Sebastiano Serlio, ilustraciones de las escenas a) cómica, b) trágica y c) satírica. «Tratados sobre los esce narios», Los siete libros de arquitectura, 1584.

construido en 1539 en el Palacio Da Porto, en Vicenza. A partir de las leyes acústicas que ofrecía el tratado de Vitruvio, el bolońés concibe la cavea con dos sectores de gradas: uno semicircular y el otro con una curvatura más abierta y similar a la de la elipsis. Divide también la orquesta en dos zonas: la plaza de la escena y la plaza del teatro; ubica el escenario elevado del suelo y a la altura de los ojos, y sugiere que se subdivida a su vez en dos partes: una anterior, plana y suficientemente sólida para soportar el peso de los aparatosos ingenios de los intermedios, de los bailarines y acróbatas de las moriscas; una zona posterior, levemente inclinada, para favorecer el escorzo de las casas en perspectiva. Además de apoyarse en la pendiente, sus perspectivas ganan profundidad en la medida que las casas van disminuyendo en altura hacia el fondo, y las más próximas a la parte anterior de la escena ofrecen dos lados, uno paralelo al frente de la escena y otro oblicuo hacia el interior. Frente al mecanismo vitruviano de bastidores ilustrados, la escena serliana ofrece la posibilidad de ganar realismo con las casas tridimensionales y profundidad con las que están dibujadas en perspectiva. Por razones de comodidad, menos escaleras que subir y mayor fluidez del espectáculo, establece los siguientes criterios para distribuir a los espectadores en la cávea: a los pies de las gradas, en los límites del zócalo, están los escańos de los más nobles; las primeras gradas están asignadas a las mujeres, según su rango; luego los hombres menos nobles, y luego, sucesivamente, el resto de las personas. ${ }^{10}$

Cuando hubo descrito las normas y los consejos de orden escenográfico y prospectivo, prometió hablar sobre el modo de iluminar la escena, tema que aborda en el apartado final del tratado, «Sobre las luces artificiales en los escenarios». Es su interés fundamental explicar cómo obtener luces capaces de

10. Pinelli (1973:17-19). 


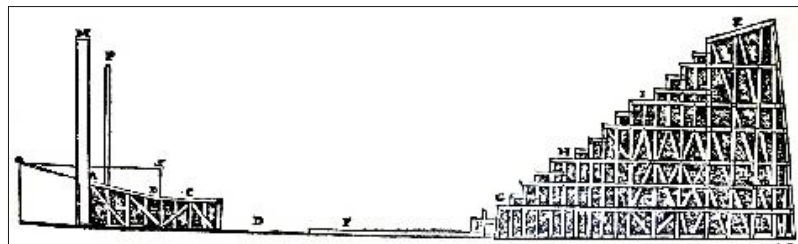

a

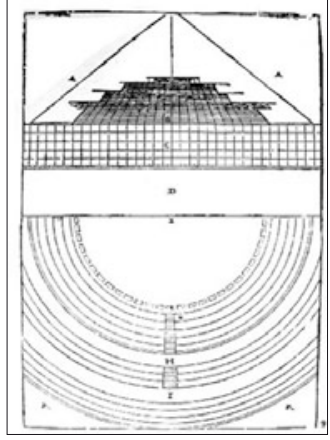

$\mathrm{b}$

Figura 5

Sebastiano Serlio, a) Corte transversal del teatro y b) planta de la cávea y el escenario. «Libro II», Los siete libros de arquitectura, 1584.

reproducir el brillo y los colores de las gemas: en unas burbujas (esferas) de cristal llenas de agua debe diluirse un trozo de sal de amoníaco si se quiere reproducir el color celeste del zafiro, y a éste, a su vez, debe ańadirse un poco de azafrán si se quiere el de la esmeralda. Para el rubí, nada mejor que el vino tinto, y el vino blanco para el ágata verde y el topacio. Las luces blancas, que son las adecuadas para iluminar el escenario, también pueden filtrarse a través de las esferas, pero con agua destilada, y deben disponerse de forma especial, a saber, detrás de la parte pintada del escenario, en un panel delgado y con orificios que permitan una distribución homogénea de la luz. Por último — explica—si se quiere obtener un rayo de sol refulgente, se debe enfrentar una antorcha a una palangana. En la apostilla también explica detalladamente cómo producir otros trucos escénicos: el fingimiento de ruidos, la materialización de fenómenos atmosféricos, la representación de procesiones de músicos o caballeros simulada en cartón, y también el paso del sol o de la luna, si se quiere explicitar la unidad de tiempo de la fábula a través de un efecto escenotécnico.

En la Práctica de la perspectiva (La pratica della perspettiva) de Daniele Barbaro, 1569, está contenida, en su Cuarta parte, la descripción de los tres tipos de escena que había formulado Serlio: quizá, por ello, Barbaro reconoce que no es necesario dibujar nuevas, porque otros ya lo han hecho. Lo que distingue al tratado de Barbaro es la ubicación del punto de fuga, que Serlio había centrado entre los parámetros geométricos del escenario, y que Barbaro reubica en la pared de fondo de la escena, es decir, elabora la perspectiva a partir de un plano. Barbaro ofrece además un método, del cual no se declara su autor, que permite armonizar las piezas de bulto del escenario con las pinturas de los muros y bastidores: se trata de un hilo que, fijado a un clavo en el punto de fuga, sirve de guía para delinear las paredes de las casas anteriores y de cualquier otro objeto traído a primer plano. 
Un último tratado favorece la visión panorámica del conjunto de propuestas sobre la escena: se trata de Las Reglas de la perspectiva práctica (La prima Regola della prospettiva Pratica) de Jacopo Barozzi da Vignola, que se publica en Roma en 1583, con los comentarios de Egnazio Danti, traductor y comentarista de la Óptica de Euclides, editada en 1573. En el prefacio a la edición de Las reglas, Danti admite que, pese a la ascendencia de la geometría sobre la perspectiva (tal como la estudia Euclides), la correcta práctica de la perspectiva exige tener en cuenta la posición del ojo humano. Dedica al teatro un capítulo que titula $\mathrm{Del}$ escenario, o del modo en que se debe dibujar la perspectiva en la escena, para que lo que se finge en la pared concuerde con lo que se dibuja en las casas verdaderas, que se disponen en relieve sobre la escena, y recalca que ambas proyecciones deben partir de un único punto de fuga, y no de dos (uno para lo plano; otro para lo tridimensional) como proponía Serlio. Aunque Danti reconoce la autoridad de Barbaro, dedica esa parte de su propuesta a elaborar una formulación teórica más completa. El aporte de mayor relevancia de su tratado es la disposición que hace de los periactos vitruvianos en la escena: ubica uno grande en el fondo del escenario, y dos a cada lado. Los prismas están colocados en forma de triángulo, cuya base es necesariamente la pared de la escena. Contempla la posibilidad de que se requieran más de tres cambios de escenario y ofrece los detalles técnicos para la sustitución de las caras de los periactos. ${ }^{11}$

La evolución de las técnicas de la perspectiva aplicada a los planos favoreció enormemente a la escena teatral y permitió la evolución de los antiguos términos hacia nuevas formas y requerimientos. Así, los periactos de Vitruvio se transformaron en un decorado de fondo de perspectiva ilusionista, en el que poco a poco se fueron incluyendo cuerpos tridimensionales. Lo que en principio pretendía resolver aspectos técnicos de proporción entre lo real y lo figurado, terminó por constituirse en un elemento fundamental de la puesta en escena, a la que se le aplicó el concepto de verosimilitud aristotélica, y para favorecer la coherencia de la representación, se buscó armonizar todos los elementos del escenario. La dificultad, sin embargo, apenas comenzaba y la complejidad crecería con la necesidad de ofrecer nuevo artificios escénicos para asombrar a los espectadores. Al describir algunos teatros efímeros y el Teatro Olímpico de Vicenza volveré sobre este espinoso tema.

11. González (2001). 


\section{Los teatros efímeros}

Mientras los críticos quinientistas se dedicaban a la recuperación anticuaria y a la lectura de la letra vitruvianas, se hacía teatro, se practicaba teatro. Los lugares para la representación fueron múltiples hasta cuando se construyeron los primeros teatros estables: salones, patios, galerías, jardines y odeones eran adaptados para montar un escenario y alojar al público. También las calles y las plazas; las riberas y las explanadas eran ocasionalmente espacios para espectáculos, torneos o naumaquias. La decoración del escenario podía ser más o menos grandiosa, dependiendo de la importancia de la celebración que la hubiere motivado, pero siempre la disposición general de la sala se realizaba con estructuras precarias, efímeras, removibles y usualmente hechas en madera. Esas estructuras debían ser adecuadas a las necesidades intrínsecas de un determinado espectáculo y a un espacio preestablecido y construido para otros fines. Las soluciones acomodaticias derivaban mayormente de los límites impuestos por la forma del terreno o de la habitación escogida como lugar de la representación. Esta circunstancia fue aceptada y promovida durante más de dos siglos, incluso hasta la edificación de los primeros teatros estables, que se construyeron en el interior de edificios preexistentes. A la consecución de un modelo de teatro permanente contribuyen, como ha habido ocasión de señalar, las preceptivas de los tratados comprehensivos de poética y la aplicación de las nuevas leyes de perspectiva que conferían plasticidad al escenario, pero también lo condicionaron, y con un grado de afectación que ha sido a menudo desestimado, la tipología arquitectónica de las habitaciones de la corte y, sobre todo, el coto que imponían sus linderos. De forma análoga, habría que conceder un margen de influencia al hecho de que una misma habitación debía acoger diversas prácticas teatrales y espectaculares. Ser capaz de justas y torneos, y de representaciones de inspiración clásica, con sus intermedios correlativos. Fueron los jardines, las galerías y los patios lugares predilectos para este fin, pues hallaron en ellos las mayores cualidades de derivación múltiple. Con pocos ejemplos me referiré a la forma, a la capacidad escenotécnica y a la cabida de espectadores de algunos teatros efímeros del siglo XVI, en Florencia, Ferrara, Roma, Mantua y Vicenza; cortes en las que la práctica teatral alcanzó una expresión prefigurativa. Omitiré, sin embargo, la descripción de la escenografía, sobre la cual se ofrecieron las prescripciones generales al comentar los tratados de arquitectura. Las indicaciones sobre las formas de disponer y decorar el escenario tuvieron sobre la práctica una incidencia mayor que las variantes ofrecidas para la constitución del teatro.

Al comienzo del siglo, en 1501, llama la atención la construcción de una gradería esquinera en un salón del Palacio Ducal de Mantua. En el vértice opuesto de la sala se levantaba el escenario decorado con cartones ilustrados en perspectiva arquitectónica. ${ }^{12}$ Se trata de una de las pocas y tempranas disposiciones ideadas

12. Tafuri (1987: 56) y Ricci (1971: 73). 


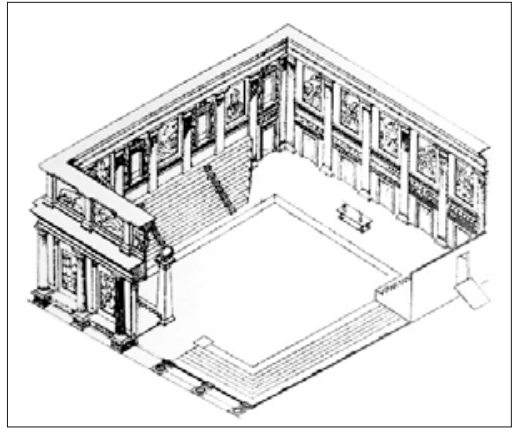

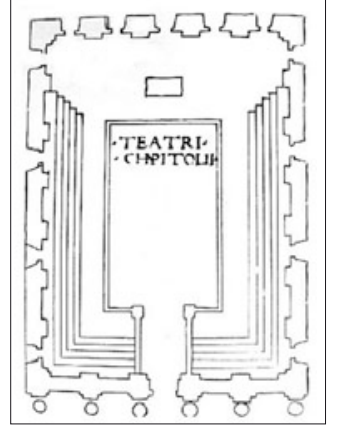

b

Figura 6

a) Alzado del Teatro Capitolino (1513) según reconstrucción de Arnaldo Bruschi, 1969; b) Pietro Roselli, planta del teatro Capitolino (1513)

para permitir desde el auditorio una visión totalmente frontal del espectáculo y para reducir la distancia entre el auditorio y el palco-escénico. También la Sala de las Audiencias del Palazzo della Ragione, en Ferrara, fue transformada en teatro provisorio en tiempos de Isabella d'Este. Su forma era rectangular $(58,40$ por 18,40 metros); en sus lados más largos estaban las gradas, y en uno de sus lados más cortos, el escenario, rematado con un muro de madera, similar a los muros de las ciudades, y con la representación de las casas de los civiles en perspectiva. El auditorio tenía capacidad para tres mil personas. En 1513, en el Palacio Ducal de Urbino se representó la Calandria de Bibbiena, la primera obra escrita en italiano vulgar. La escenografía de Girolamo Genga reproducía la ciudad no sólo en tela sino con algunos relieves (un templo octogonal, un arco triunfal); interesa destacar que el palco rodeaba el escenario de la misma manera que los fosos circundan las murallas de las ciudades. "Como el foso de la tierra», escribió Castiglione al obispo Ludovico Canossa para explicarle cómo la ciudad que reproducía el escenario se extendía hacia el auditorio. ${ }^{13}$ De esa misma fecha data la primera estructura autónoma y pública destinada a albergar los espectáculos de Roma, el teatro líneo del Campidoglio. Su planta era rectangular y ocupaba, casi íntegramente, toda la plaza. La cavea era también rectangular y se apoyaba sobre siete escalones. La pared de la escena la constituían varias columnas, entre cuyos recuadros se alternaban ventanas o pendones dibujados con imágenes. Dos puertas laterales servían para dar entrada y salida a los actores. Al igual que los teatros grecorromanos, la edificación carecía de techo, y aunque solía utilizarse a cielo abierto, eventualmente el teatro podía cubrirse con una carpa. Tres mil espectadores se disponían entre la platea y las gradas.

13. También en Ricci (1971:75-76). 


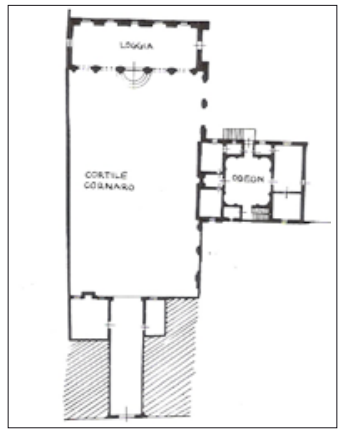

Figura 7

Planta del patio de Casa Cornaro, con la galería y el odeón.

Ejemplo emblemático de la incidencia de la arquitectura cortesana en la configuración del edificio teatral es la obra del arquitecto Gian Maria Falconetto, hecha por encargo del humanista veneciano Alvise Cornaro. El complejo exterior de la Casa Cornaro (1524) — conformado por el conjunto de galería, patio y odeón- fue concebido especialmente para la realización de espectáculos. En 1556, Alvise Cornaro describe el teatro de Falconetto «a imitación de los antiguos [teatros]", con un «escenario [hecho con] piedra perpetua», pero con una zona para "los que escuchan fabricada con tablones que se pueden remover». ${ }^{14}$ La estructura de piedra adosada a la galería ha sido considerada uno de los primeros intentos por erigir un teatro permanente. Cinco arcos sostenidos por sus respectivas columnas reproducían la frons scaenae latina; el escenario se ubicaba en el centro de la galería y ocupaba una quinta parte. Aunque la loggia y el foso de la orquesta fueron elementos recreados a partir de las indicaciones vitruvianas, la forma rectangular de la planta en nada imitaba las atribuciones funcionales del anfiteatro romano; por el contrario, forzaba un aprovechamiento del espacio que no favorecía al espectador ni unificaba operativamente escenario y auditorio. La relación entre las dimensiones del patio y las del lugar de la representación es desmedida, aun cuando ha de suponerse que el patio no era todo auditorio y que la representación podía, de manera episódica, tener lugar en el centro del vano. Si bien el complejo fue ideado ex novo, la función de su estructura se correspondía con la establecida para esa parte del edificio, aunque eventualmente aceptara otra, como la representativa.

14. Zorzi-Innamorati-Ferrone (1982:7), Attolini (2000:65) describe dos obras encargadas por Cornaro al arquitecto veronés, un teatro, en Fossan de Loreo (Teatro de Loreo), Polesine (hoy provincia de Rovigo), y el conjunto exterior de la casa Cornaro. Sobre la localización del teatro descrito en la carta de Cornaro al duque
D’Este (1556) las posturas son divergentes: teóricos como Giuseppe Fiocco o Ludovico Zorzi ubican el escenario de piedra en la galería de la Casa Cornaro, mientras que Licisco Magagnato, en su monografía Teatri italini del Cinquecento (1954), y Giuliana Ricci (1971:74) lo emplazan en la obra hecha en Rovigo. 
Hacia 1541, la corte florentina le encarga a Vasari, con la asistencia de Bernardo Buontalenti, la transformación del Salón de los Quinientos del Palazzo della Signoria en un aula regia para la representación. Seis años después, y hasta 1569, los trabajos de la sala habían concluido la edificación de un escenario con un arco escénico semicircular y un área detrás del palco-escénico para músicos y actores, tal vez las primeras estructuras acondicionadas para ese fin durante el Cinquecento. ${ }^{15}$ El palco-escénico tenía cinco periactos y un telón. En su parte posterior, el escenario se inclinaba con una pendiente descendente hacia el público (la misma pendiente que describe Serlio en su tratado), y a su vez, el pavimento del auditorio se inclinaba hacia el proscenio, orientación que representa una de las mayores innovaciones que ofrecía la sala. ${ }^{16}$ Toda el área del teatro (escenario y gradas) tenía forma octogonal alargada. En el auditorio, la distribución de los asientos del público era la usual: seis hileras de gradas — que simulaban la piedra - paralelas a los lados no ocupados por el escenario. ${ }^{17} \mathrm{El}$ cuarto lado restante debió destinarse para el palco de los príncipes o para la entrada al recinto. En 1586, Buontalenti reproduce buena parte de ese modelo en el teatro mediceo erigido en el salón del ala oriental del Palazzo Uffizi, del que se conserva una ilustración que realizó Jacques de Callot. El grabado representa el momento del baile de los matachines sobre el escenario y fuera de él, y evidencia la forma en que había de distribuirse el público en salas de este tipo. ${ }^{18}$

Siempre en Florencia, el jardín Boboli del Palazzo Pitti, construcción iniciada en 1550 y ampliada varias veces en el transcurso de cien años, fue concebido por Buontalenti y Alfonso Parigi como un espacio múltiple. El área verde, que en el centro tenía un gran estanque, se conectaba con un patio y éste a su vez con un anfiteatro, el último edificio creado para el conjunto. Numerosas son las crónicas que reseńan los espectáculos realizados en los distintos sectores

15. En el teatro griego, la antigua skené fue la zona destinada para resguardar a los histriones o colocar la utilería necesaria para la escenografía. En el siglo XVI, la invención del arco escénico también ofrecía una finalidad práctica: la de ocultar las luces y los ingenios necesarios para los efectos especiales. Era además el lugar donde se recogía el telón. Attolini (2000: 74) le atribuye también una función ideológica, la de separar o enmarcar el espacio de la ficción teatral.

16. Zorzi (1977: 109), Attolini (2000: 76-77).

17. Cruciani (1992/2003: 21) y Attolini (2000: 76).

18. También en Florencia, el segundo patio del Palacio Medici fue en 1539 acondicionado por Bastiano da Sangallo para la representación de la comedia Commodo de Antonio Landi.
Interesa destacar que Sangallo se esforzó por reproducir en el patio la apariencia de un salón y recubrió toda el área con una carpa, a la manera del velarium romano. Sobre los lados más largos del patio se erigieron las tribunas destinadas a las mujeres, mientras que los hombres se sentaban en unos bancos al centro y frente al escenario, pero todos a su vez alrededor del palco central de los príncipes, elevado sobre el resto de las estructuras. La mayor parte del público debía observar la representación desde un nivel más bajo que el del escenario. También se sabe que los actores que no estaban en escena esperaban su turno sentados en la primera fila de la tribuna y accedían al palco-escénico por medio de escalinatas removibles. Vid Attolini (2000: 67). 


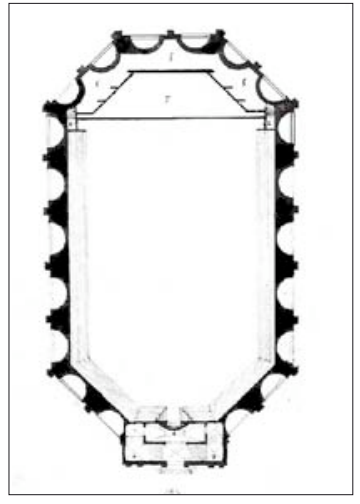

a

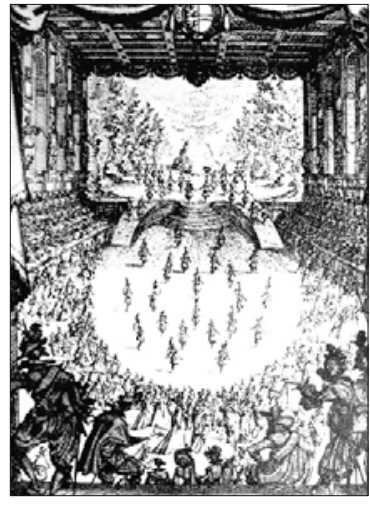

$\mathrm{b}$

Figura 8

a) Giorgio Vasari, el joven, proyecto de sala para comedias, 1598, Gabinetto disegni e stampe degli Uffizi. b) Grabado de Jacques de Callot, Teatro Uffizi durante la representación de un intermedio con escenografía de Giulio Parigi, 1616.

y, en ocasiones, en todos a la vez. ${ }^{19} \mathrm{El}$ jardín era lugar predilecto para los torneos que frecuentemente concluían en naumaquias, mientras que el patio era la antesala donde se hacían los espectáculos musicales y las representaciones teatrales. En el anfiteatro contiguo tenían lugar los combates de lanza o estoque. Es significativo el modelo utilizado para la planta del anfiteatro, que reproduce la forma rectangular y la orientación vertical de los salones y los patios. El auditorio contaba con dos tribunas laterales enfrentadas.

No obstante, un número menor de obras, de las que se conservan algunos proyectos en forma de bocetos, dan cuenta de un movimiento a contracorriente, preocupado por concebir otro tipo estructura para el espacio escénico, más bien dirigida a recuperar las indicaciones sustanciales de la obra vitruviana, sobre todo en lo relativo a la unión del escenario con el auditorio. Son realizaciones que adoptan para ello la forma de una planta circular o semielíptica. Los teatros de Andrea Palladio anteriores a la edificación del Olímpico de Vicenza son ejemplo de esa inquietud. Entre 1561-1562, Palladio acomete la transformación de una sala del Palazzo della Ragione de Vicenza en un teatro provisional «en todo igual al de los antiguos», ${ }^{20}$ y en Venecia, en el Convento de la Caridad, para la Compañía de la Calza, entre 1564-1565, instaló en el patio un «mezzo palazzo di legname

19. Sobre los espectáculos y los decorados realizados en el complejo exterior del Palazzo Pitti véase Molinari (1968) y la edición original de Le nozze degli Dei (1637), disponible en el catálogo digital de la Biblioteca de la Universidad de Turín.
20. Attolini (2000: 87-88) afirma que el teatro del Palacio de la Razón es probablemente el mismo que el de la Basílica vicentina, sobre el que trataré más adelante al describir el Teatro Olímpico. 


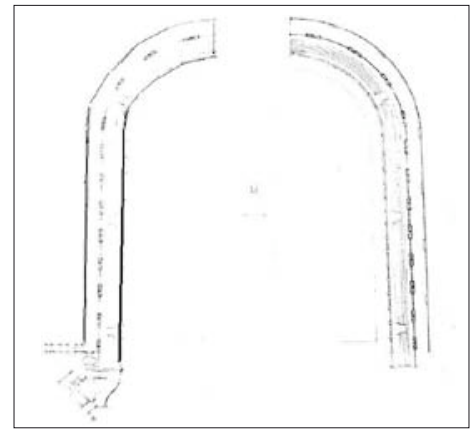

Figura 9

Planta del anfiteatro, Jardines Boboli (1550-1560), Florencia

ad uso di Colosseo». Por último, se ha identificado en el dibujo palladiano de la planta del Teatro de Verona el epítome de su concepción de los auditorios elípticos. También Giacomo Barozzi da Vignola, en 1560, en el Palacio Farnesio de Piacenza, dejó proyectado un teatro estable que hacía las veces de patio del palacio, con un auditorio ovalado. En los primeros años del siglo se atribuye a Leonardo da Vinci la invención, tal vez nunca realizada, de un teatro redondo con un escenario giratorio. ${ }^{21}$ Estos planteamientos acusan una intención de romper con el esquema impuesto por el uso y la costumbre de adaptar la sala teatral a un cuerpo arquitectónico predeterminado, y allanaron el camino hacia estructuras más eficaces, capaces de subordinar las limitaciones espaciales a las necesidades operativas.

La forma de un número predominante de teatros provisorios evidencia que arquitectos y escenógrafos concedían una relevancia desigual a la realización del escenario (la aplicación de las reglas de perspectiva en la escenografía, la disposición de las piezas de bulto, la invención de máquinas para los efectos especiales o la ubicación de las luminarias), frente a la disposición del auditorio, la localización de las graderías y la orientación del público hacia la representación. En la planimetría de los teatros provisionales descritos, y también en la de muchos otros, es recurrente la preeminencia del rectángulo. En esas estructuras rectangulares, cuyos lados más largos eran a menudo seis veces mayores que sus lados más cortos, se colocaban las graderías del auditorio indefectiblemente de dos maneras, o mediante un diseńo mixtilíneo en forma de $U$ alargada o con dos cuerpos de bancos enfrentados. Es notable la falta de proporción entre las medidas de las partes del teatro, así como la pérdida de la noción de la cávea grecorromana. El auditorio de los teatros provisorios carecía de una visión central y obligaba al espectador a adoptar una postura corporal antinatural para poder orientarse hacia

21. Ricci (1971: 72 y 86). 


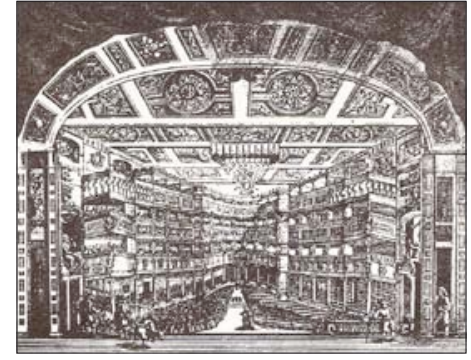

Figura 10

Ferdinando Tacca, Ilustración del auditorio del Teatro de la Pérgola, Florencia, 1657.

el escenario. Ese modelo de cávea en forma de $U$ alargada se repetirá en varios de los primeros teatros estables, como el Teatro delle Saline, Piacenza (hacia 1592), el Teatro Farnesio de Parma (1618-1628), acondicionado en el Salón de Armas del Palazzo di Corte, y el Teatro de Falcone, Venecia (1652). No será hasta mediados del siglo xvil que se sustituya ese modelo por la cávea en forma de herradura, que ofrece una curva más abierta y más cercana a la media circunferencia. Las tribunas elevadas y reservadas a los príncipes (el exagerato pulpito que describe Pellegrino Prisciano) fueron también sustituidas por estructuras superpuestas detrás o a los lados del auditorio, encepadas a los techos y las paredes, hasta alcanzar cuatro o más niveles de altura. Estos balcones (palcos), divididos a su vez en pequeños compartimientos privados, fueron una solución constante en los edificios teatrales a partir de la década de los cincuenta, y permitieron contener a un mayor número de espectadores, pues fue sólo hasta ese momento que los teatros adquirieron nuevamente su sentido de espacio para las masas. ${ }^{22}$ La denominación teatri a palchetti es sinónimo de teatro all'italiana; remite concretamente a las tipologías arquitectónicas del escenario y de la sala que definieron la estructura de los teatros estables, y no tanto a las otras acepciones con las que frecuentemente se invoca el término all'italiana para investir al teatro de valores simbólicos o culturales. La solución balconada constituye, en sentido amplio, la aportación estructural más relevante que aún se conserva en la actualidad. ${ }^{23}$

22. Utilizo el término espacio para las masas y no el de espacio público, pues el ingreso al teatro era pago para los puestos de la platea y para las plazas de los balcones, que eran directamente propiedad de los cortesanos. Craig (1972: XLI). 23. Las plantas, los cortes y los alzados de un número significativo de teatros europeos del siglo Xvil fueron reconstruidos por Edward A. Craig para completar aquellos del Tratado sobre la estructura del teatro y la escena (1676), de
Fabrizio Carini Motta. Las salas tenían forma de U, de V, de campana, de óvalo, de círculo, de doble elipse. La más recurrente fue hasta finales del xviII la de herradura. Sobre la incidencia de la forma de los teatros en la acústica véase también Craig (1972: xxx-xxxi) y, más recientemente, Quaglianini (2008), para los proyectos de las estructuras líneas de las máquinas, de las salas y los escenarios de los primeros teatros estables. 


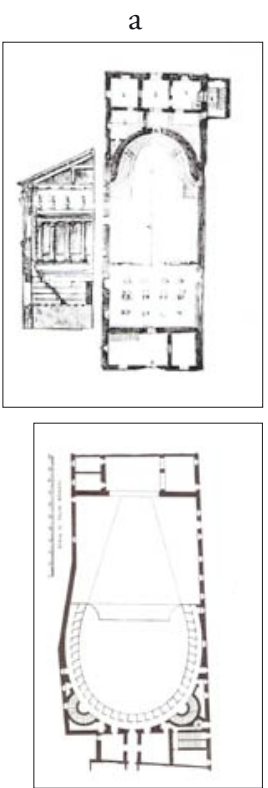

d
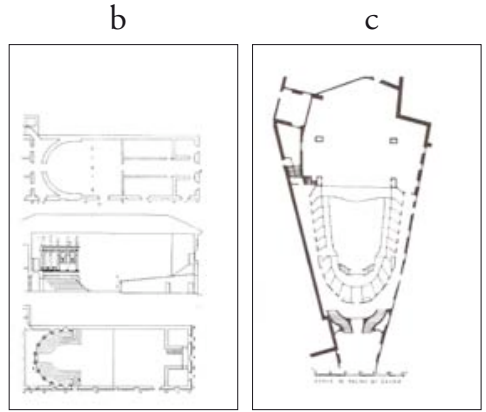

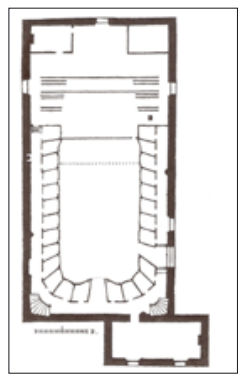

e

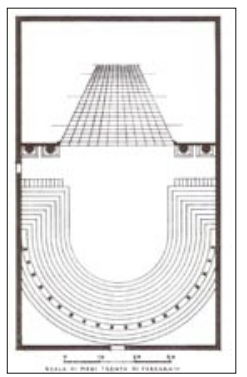

f

Figura 11

a) Planta y alzado del Teatro Sabbioneta, 1588, ilustración de Carlo D’Arco, hacia 1850,

Archivo del Estado de Mantua; b) Teatro de Sabbioneta, 1588, planta del nivel inferior al palco-escénico; corte transversal del escenario y el auditorio, planta del nivel superior de la galería. Ilustraciones de Ugo Polazzo, 1956; c) Planta del Teatro del Falcone,

1652, Arq. Giovanni Angelo Falcone, Génova, reconstrucción de Edward A. Craig basada en ilustraciones de la Biblioteca Nacional de Turín; d) Planta del Teatro

Tor di Nona, 1670, Arq. Carlo Fontana, Roma, reconstrucción de Edward A. Craig a partir de las ilustraciones del archivo del Sir John Soan Museum de Londres;

e) Planta del Teatro delle Saline, Piacenza, 1592, reconstrucción de Edward A. Craig a partir de ilustraciones de la Asociación Amici dell'Arte di Piacenza;f) Planta del Teatro degli Intrepidi, 1606, Arq. Giovanni Battista Aleotti, reconstrucción de Edward A. Craig a partir de una ilustración de la Biblioteca Estense de Módena. 
a
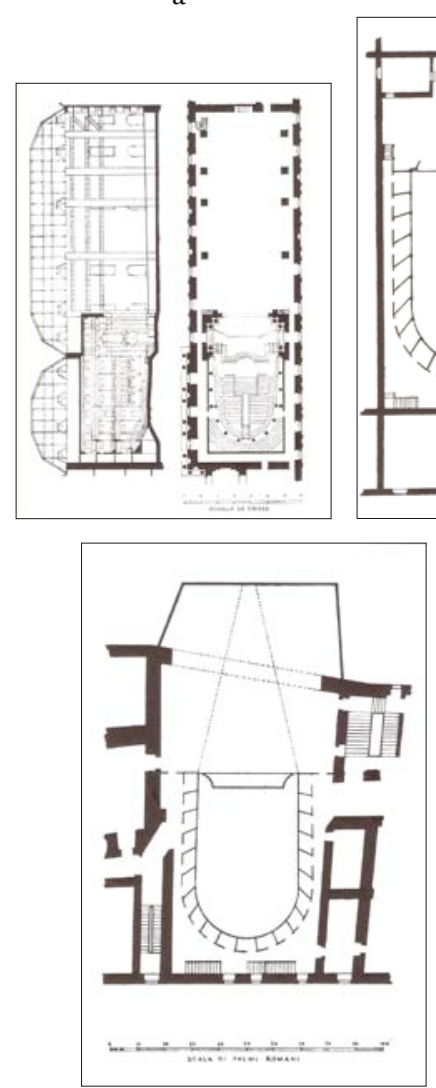

$\mathrm{e}$ b

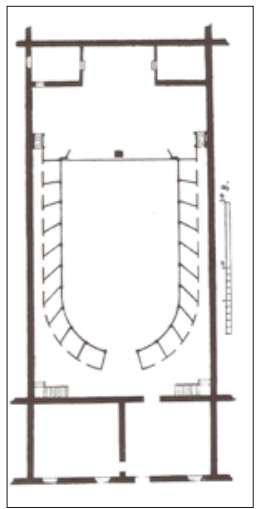

C

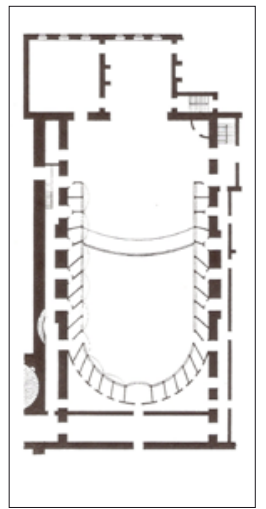

d

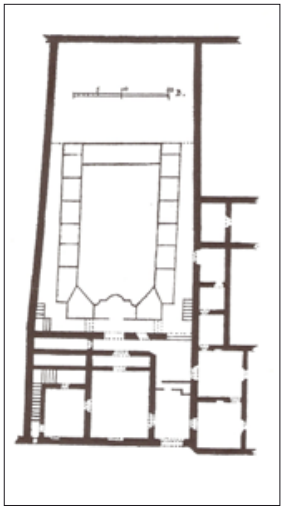

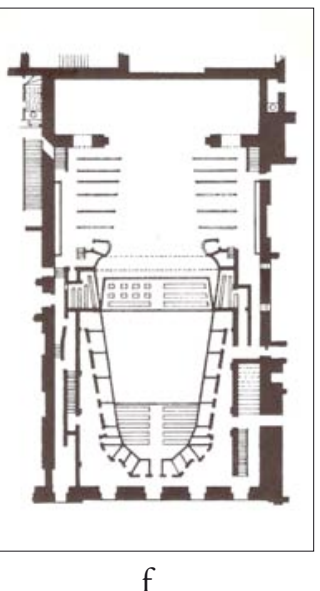

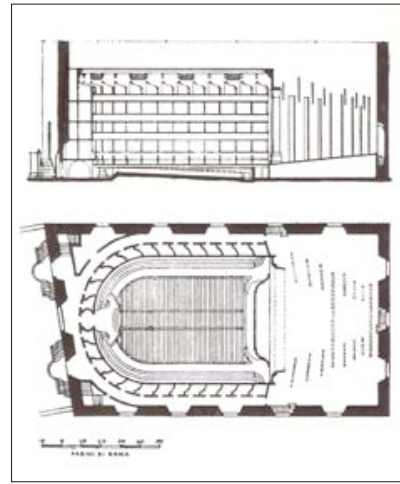

g

Figura 12

a) Corte transversal y planta del Théâtre des Machines, París, 1662, Arq. Gaspare Vigarani, reconstrucción de Edward A. Craig a partir de grabados de J. F. Blondel;

b) Planta del Teatro della Racchetta, Parma, 1652, reconstrucción de Edward A.

Craig a partir de ilustraciones del Archivo del estado de Parma;

c) Planta del King's Theatre, Londres, 1704, Arq. John Vanburg, reconstrucción de

E. A. Craig por grabados de George Saunders; d) Planta del Teatro Fedeli

(o Teatro delle comedie), Mantua, 1669, Arq. Carini Motta, reconstrucción de

Edward A. Craig a partir de ilustraciones del Archivo del estado de Mantua;

e) Planta del Teatro Tor di Nona, Roma, hacia 1660, reconstrucción de E. A. Craig a partir de grabados de Felice Giorgi; f) Planta del Salón de la Ópera del Palais Royal, París, del proyecto de 1672 del Arq. Carlo Vigarani, reconstrucción de E. A. Craig a partir de grabados de J. F. Blondel;

g) Corte transversal y planta del Teatro degli Intronati, Siena, su primera proyección data de 1560 por obra de Bartolomeo Neroni; la segunda es de 1670 por G. B. Piccolomini. Reconstrucción de E. A. Craig basada en ilustraciones del archivo del Sir John Soan Museum de Londres. 


\section{El teatro olímpico de Vicenza}

El Teatro Olímpico de Vicenza, inaugurado el 3 de marzo de 1585, es entre los teatros estables del Cinquecento el más temprano que haya pervivido hasta nuestros días, y por ello suele considerársele el primero de la historia moderna, aunque hay sobradas noticias de la existencia de teatros de corte y teatros públicos (o stanze) desde los ańos cuarenta. ${ }^{24}$ Sobre el hecho de su antigüedad priman, sin embargo, muchas cosas. La relevancia de la obra de Andrea Palladio es fundamentalmente arquitectónica, como se verá, por constituir un modelo único de teatro, por despejar los problemas técnicos (matemáticos) de la realización artística de la escenografía y, sobre todo, por conjugar cumplidamente el escenario con el auditorio. El Teatro Olímpico ultima de forma positiva aspectos fundamentales que venían guiando, y lo siguieron haciendo, la búsqueda de los arquitectos-escenográfos. Sobre todos estos temas volveré más adelante. Pero también es relevante porque su constitución puede asociarse con conceptos de otro orden, como, por ejemplo, con la reinterpretación del ideal clasicista de su tiempo, o con la significación que alcanza en la historia de las formas y de las teorías del espacio escénico, o, en términos de tradición, con la identificación de tipologías que permitieron restituir la imagen de otros teatros del siglo Xvi.

Cuando el 10 de agosto de 1579 la Academia Olímpica de Vicenza determinó la construcción de un edificio que fuera a la vez «habitación de la Academia y teatro y escenario de perpetua conservación para la realización de espectáculos públicos», ya Palladio había sido el arquitecto del teatro provisional que se había construido en el Salón de la Basílica para la representación del Amor constante de Piccolomini, y luego para la Sofonisba de Giangiorgio Trissino, último montaje (1562) hecho por los académicos vicentinos. ${ }^{25}$ Junto con los teatros del Convento de la Caridad y del Palacio de la Razón, las ilustraciones al Vitruvio de Daniele Barbaro y los dos escenarios ahora descritos, es posible imaginar que el arquitecto ya hubiese prefigurado una idea de teatro previa a la edificación de su obra postrera. De hecho, es sabido que Palladio aceptó el encargo ese mismo año de 1579, y que murió al año siguiente, cuando el teatro no había sido concluido, pero sí proyectado casi en su totalidad. La obra fue llevada a término por Vicenzo Scamozzi, quien supervisó la construcción y dispuso el sistema de iluminación de todo el recinto. ${ }^{26}$ En 1588, Scamozzi ejecutaría su propio modelo de teatro en Sabbioneta, para el que retomó, sin embargo, algunos

24. Teatro Spelta, Módena (1539); Teatro de la Sala, Bolonia (1547); Teatro de las Salinas, Génova (1550); la sala de las Comedias, Reggio Emilia (1568); los dos teatros de San Cassian, Venecia, operativos en 1581, y el Teatro Nuevo (o Tron), inaugu- rado el Carnaval de 1581. Benevolo (1973: 882).

25. Puppi (1973: 22) y Perelli (2002: 68).

26. Sobre la cuestión de la posible autoría de Scamozzi en la concepción de las perspectivas, véase Attolini (2000: 93-94). 


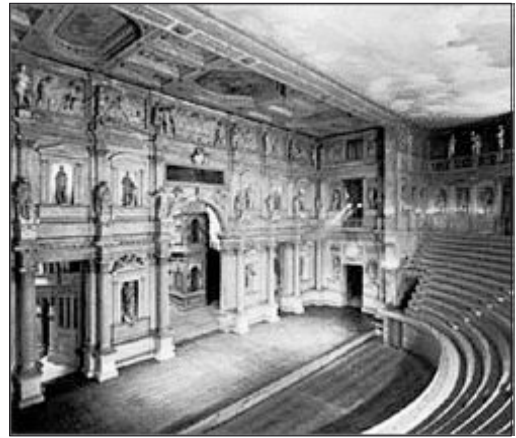

Figura 13

Teatro Olimpico de Vicenza, Vicenza. Vista actual.

elementos formales del Olímpico de Vicenza. El Teatro de Sabbioneta es el primer edificio teatral autónomo que se conozca, por no haber sido edificado dentro de los límites de otras estructuras. En todo caso, el proyecto palladiano prefiguraba para el teatro vicentino un ambiente cerrado y coherente, en el que cada elemento estaba estrechamente unido con los restantes. Para comenzar por lo primero, será necesario atender a la descripción de sus características y a la función de cada una de las partes de su estructura.

Todo el teatro ocupa una superficie irregular (33,50 por 22 metros). Los materiales utilizados para su edificación fueron el ladrillo para las paredes, las columnas y cualquier otro elemento de la estructura; la piedra para las bases y los capiteles; la madera para la cávea y el estuco para las estatuas. Materiales que a diferencia del mármol y el bronce, más ricos y populares en la construcción de edificios monumentales, favorecen la resonancia acústica.

El teatro consta de cuatro partes: una zona para el público, el foso de la orquesta, el proscenio donde se realiza la representación y un sector detrás de este último para la escenografía, constituida por una prolongación de calles con casas y edificios. Entre el proscenio y la escenografía se levanta la pared de la escena (o scenafronte) con tres aberturas principales: la puerta regia, más grande y al centro, y dos puertas menores (hospitalia) que la flanquean. ${ }^{27}$ Otras dos entradas se ubican en las versurae, para sumar un total de cinco puertas y cinco puntos principales de atención y observación para el espectador. Toda la scenafronte está decorada por columnas y estatuas en bajorrelieve, y por nichos con estatuas en altorrelieve. Se identifican tres zonas superpuestas y divididas por cornisas. En la

27. Se ha visto en la zona central dominada por la porta regia una derivación del arco triunfal que ya Palladio había realizado en los aparatos de 1574, para la entrada triunfal a Venecia de Enrique III de Valois. Ricci (1971: 87-88). 


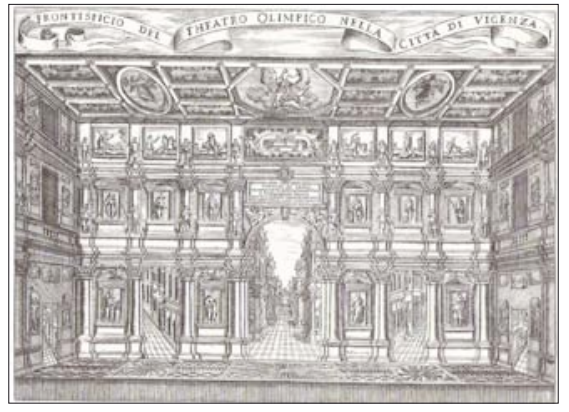

Figura 14

Giacomo Ruffoni, Escenario del Teatro Olimpico de Vicenza, grabado en cobre, hacia 1650 .

última de estas zonas, las esculturas representan las tareas de Hércules. El techo del proscenio consta de artesones igualmente repujados.

La zona de los espectadores tiene forma semielíptica y constituye el punto de observación más alto del conjunto; está conformada por 13 filas de gradas y tiene capacidad para 380 personas. Detrás de la última fila se levanta una balaustrada rematada por estatuas. El techo del auditorio recrea el cielo con sus nubes y sugiere la sensación de estar a cielo abierto, como en los teatros de la antigüedad. El foso de la orquesta está adosado a la cávea para reflejar el sonido hacia la audiencia. Se ubica, proporcionalmente, en un nivel inferior respecto al escenario y en dos en relación con el auditorio. Por su forma también semielíptica, se presenta como una prolongación de la cávea. ${ }^{28}$ De estas cuatro zonas descritas a grandes rasgos huelga detenerse en dos de ellas, en las calles detrás del proscenio (la escenografía) y en las graderías del auditorio, y, más particularmente, en la correspondencia que alcanza su relación doblemente articulada. Con ello, entre otros aspectos de relevancia, concluiré el recorrido por las prácticas y los problemas ligados a la materialización del espacio escénico quinientista.

No será necesario recapitular aquí por qué la elaboración de la escenografía estaba directamente relacionada con la idea de perspectiva — de proyección urbana en el caso de las comedias y las tragedias; campestre, en el de las pastorales-, o por qué la materia de la representación teatral debía ser extrapolable a los hechos de la realidad hasta el punto de lo verosímil; pero sí agregar al respecto que, por lo menos en términos de arquitectura teatral, todavía

28. La zona del auditorio tiene un diámetro máximo de 18,10 metros; mientras que el mínimo es de 6,65 metros. La primera fila de gradas se eleva sobre el escenario 1,31 metros y 2,71 metros sobre el foso de la orquesta, que abarca un área de 6,40 metros. Ricci (1971: 87-89), Attolini (2000: 95) y Perrelli (2002: 69). 
en la década de los ochenta no se resolvía la cuestión del lugar más idóneo para ubicar el punto de vista desde el cual el auditorio observaría las perspectivas, y que esa irresolución afectaba las proporciones del espacio recreado y, por ende, la credibilidad de la representación. Situar ese punto de vista dependía, por otra parte, de la escogencia de la forma (la tipología) del auditorio. Tampoco será preciso volver sobre la relación entre lo real y lo figurado que dominaba el concepto de teatro, o sobre los efectos de proyección y asimilación, es decir, de difusión e influencia que los varios contenidos de la obra debían tener sobre la audiencia, pero sí subrayar que la elaboración de la escenografía no escapaba a esas proposiciones.

La aplicación de la perspectiva al teatro es la más compleja de todas. Los arquitectos abocados a la escenografía entendían que las nuevas leyes de la perspectiva eran insuficientes para conferir una apariencia tridimensional a un objeto observado desde puntos de visión divergentes. La dificultad crecía de forma exponencial si se consideraba que de ser posible resolver la cuestión de los múltiples puntos de visión y de fuga, habría también que conciliar esas perspectivas con otros volúmenes superpuestos y móviles. Era el caso de los personajes que se situarían frente a las telas pintadas en escorzo, al lado de los templos en relieve, dentro de las casas tridimensionales; de la presencia de objetos dispersos por el escenario o del paso de máquinas aéreas y terrestres. La dificultad mayor era, pues, conjugar coherentemente planos y volúmenes estáticos con planos y volúmenes en movimiento. Dicho de otra manera, los escenarios en perspectiva arquitectónica exigían una fórmula que garantizara una intuición perspectiva del espacio constante, homogénea e infinita desde cualquier ángulo de visión y que fusionara todas las demás cosas sin por ello afectar la correcta percepción del espacio representado ni la continuidad óptica del escenario.

En términos de valoración simbólica, de atribución, la perspectiva se arroga las mayores cualidades ilusionistas; determina qué está arriba o abajo, delante o detrás, a un lado o al otro, y a qué distancia está el espectador de esos objetos que se suceden en el plano. Como instrumento de representación, la perspectiva establece nuevas formas de percepción y relación con el lugar recreado. Mediante la proyección perspectiva es posible no sólo extender el espacio más allá de su límite físico, sino también acercarlo hacia el observador y generar un efecto de proximidad e inclusión. Con la alternancia de estos códigos, la escenografía procuraba los mismos efectos de proyección y asimilación que se proponía alcanzar la representación.

La solución que ofrece Palladio a estas cuestiones es variada. En términos prácticos, comienza por reinterpretar el canon vitruviano hasta extremarlo. Conserva la elevación de la tribuna con respecto al palco-escénico y la curvatura del círculo que dominaba el anfiteatro, pero alarga las líneas de los bordes de las gradas hasta que converjan directamente sobre los muros laterales. El resultado es una cávea semielíptica, que ofrece mayor capacidad de espectadores que la 


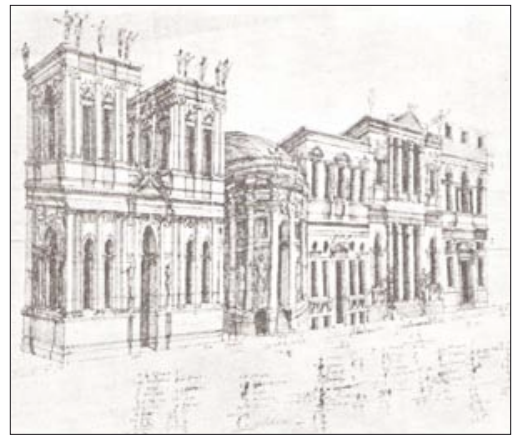

Figura 15

Vicenzo Scamozzi, Ilustración para las perspectivas del escenario del Teatro Olimpico de Vicenza, Vicenza, 1584. Colección Devonshire, Chatsworth, Londres.

circular y aun conserva la buena recepción acústica y la posibilidad de enfrentar el escenario desde todos sus diversos puntos. La distancia entre el auditorio y el palco escénico es la menor entre las medidas de todas las partes del teatro. La relación de frontalidad constituye el primer mecanismo de unión entre el auditorio y el escenario; el segundo es de orden visual y está determinado por la escenografía. Desde la puerta regia, la escenografía tiene una profundidad de 13 metros y está construida en pendiente descendente hacia el proscenio. Detrás de las cinco puertas de la scenafronte antes descritas se irradian siete calles en forma de abanico; dos de las cuales se bifurcan desde la vía principal que conduce a la puerta regia. Todo el sistema de calles fugadas fue ideado para que cada parte del auditorio tuviera al menos un punto de observación privilegiado para ver recalar a los personajes en el escenario. Fue ésta la principal síntesis entre la tradición clásica y la contemporánea: conciliar la exigencia de un escenario en perspectiva arquitectónica con la de una visión igualmente favorable para todos los espectadores. La doble articulación de la cávea con el escenario se alcanza, entonces, mediante un sistema de relaciones simultáneas dadas por 1) las estructuras arquitectónicas que enfrentan al observador y con el objeto observado, 2) el efecto psicofísico de inclusión o extrañamiento que las perspectivas producen en el espectador. ${ }^{29}$

29. Panofsky (1999: 49-54) dedica su capítulo IV a la idea de perspectiva en el Renacimiento europeo, y especialmente a la valoración que pintores y arquitectos daban a los problemas matemáticos en función del objetivo artístico, que era no tanto la reproducción de un espacio dado, cuanto la relación fenomenal que debía entablar con el observador. Al hablar de la capacidad que tiene la perspectiva de pro- curar una distancia simbólica entre los hombres y las cosas, ofrece la siguiente lectura: «La historia de la perspectiva puede, con igual derecho, ser concebida como un triunfo del distanciante y objetivante sentido de la realidad, o como un triunfo de la voluntad del poder humano de anular las distancias; o bien como la consolidación y sistematización del mundo externo, o, finalmente, como la ex- 


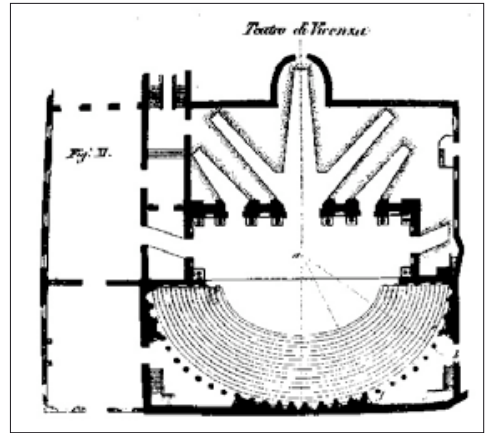

a

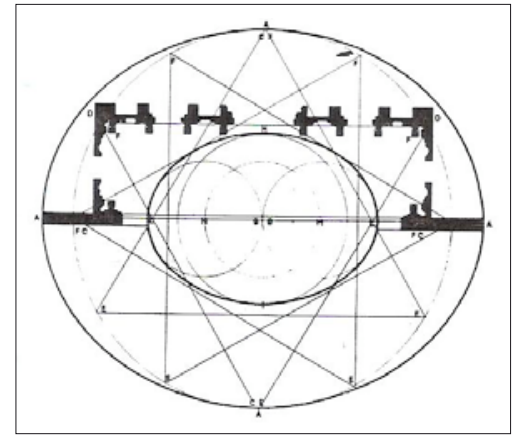

$\mathrm{b}$

Figura 16

a) Ottavio Bertotti Scamozzi, Planta del Teatro Olimpico de Vicenza, 1776.

b) Ottavio Bertotti Scamozzi, Construcción geométrica de las perspectivas del auditorio y el escenario del Teatro Olímpico de Vicenza, 1776.

Sobre si las aportaciones de Palladio alcanzaron el cabal cumplimiento de su propósito, las opiniones de contemporáneos y sucesores fueron divergentes: unos criticaron la inconsistencia en la aplicación de la perspectiva o el incumplimiento de las funciones del auditorio; otros valoraron por sobre todas las cosas el criterio regulador de la propuesta, y consideraron que aspectos como la unificación del espacio o la multiplicidad de puntos de visión privilegiados debían regir la constitución de todos los teatros.

Giovanni Vicenzo Pinelli, académico vicentino, estudioso de la óptica, comentarista del Tratado de la pintura de Leonardo da Vinci y maestro de Galilei, dejó escrito un texto breve y desenfadado sobre la representación inaugural del Teatro Olímpico (Appunti di Giovanni Vicenzo Pinelli). ${ }^{30}$ Las observaciones son varias y dispersas, pero atienden principalmente a aspectos relativos a la estructura del lugar. Desde su posición de espectador, critica la mala constitución de las partes del teatro y la incidencia que tienen esos defectos en la comodidad y, sobre todo, en la visibilidad de la audiencia. Comienza por lamentar la ausencia de baños (...nel teatro di Vicenza commodità per li bisogni naturali per gli uomini e per le donne?), sigue con una descripción sobre los problemas de ingreso y distribución del público: considera insuficientes las puertas de acceso a la edificación y al auditorio, y reclama la falta de guía y de indicaciones claras para conducir a los espectadores (...che metodo per entrar senza mettersi in pericolo, che ordini nella città per levar scandalo; che meglio: più

pansión de la esfera del yo». La reflexión sobre la significación simbólica de la perspectiva es especialmente pertinente a la práctica teatral, aunque no escapa a otras disciplinas que tam- bién requieren de un sistema de representación que alterne códigos entre el subjetivismo y el objetivismo.

30. Gallo (1973: 59-60). 
rastelli e porte o portelli; in poco tempo ammettere tutti; diverse prime porte e intrar divise secondo le qualità delle persone o per l'età, ecc...). Las consecuencias de la mala repartición alcanzaron el trato irrespetuoso a las personas (Che quasi tutti nel voler entrare si sono incontrati in qualche male: di spinte, strette; d'indugio, di cattive parole o fatti...). La confusión se extendió hasta las graderías, en las se contravinieron las normas de decoro, esto es, que los académicos parecían — según su descripción - montados a horcajadas unos sobre otros (...Nel sedere, dentro delle gambe dei superiori; incommodo, ecc.). Sobre la calidad de la observación del espectador, señala que los extremos de las gradas no tenían visibilidad hacia el escenario, pero sí — al menos, afirma - hacia los espectadores situados enfrente (Quelli che non vedeano dalle bande ultime del teatro la scena e il palco, vedeano almeno le persone del teatro tutto, uomini e donne, in faccia ecc.); que, en consecuencia, las perspectivas del escenario sólo podían ser apreciadas por quienes estaban ubicados al centro del mismo, y que incluso desde esa ubicación, las perspectivas afectaban la veracidad. Las calles por las que entraban los histriones al palco-escénico generaban un efecto de perspectiva invertida: el espectador percibía a los actores más altos al verlos venir desde lejos que llegados al plano principal. (Che le prospettive della scena non erano vedute che dal teatro di mezzo. Che nell'uscir delle persone dalle strade che calavano per centro della prospettiva, di lontano parevano giganti e nell'accostarsi si diminuivano, che dovrebbe essere il contrario).

Diez años después de la inauguración del Teatro Olímpico, Lorenzo Sirigati afirmaría en su tratado La práctica de la perspectiva (1596) "que es imposible apreciar la unión de lo fingido con lo verdadero desde todas las partes; porque no hay mediante el arte manera de situar ese punto de vista capaz de unir lo real con lo fingido». ${ }^{31}$ Para la teoría de la perspectiva central sólo es posible alcanzar la continuidad óptica si se observa con un solo ojo inmóvil. Esta fórmula pudo aplicarse con relativa sencillez a las artes plásticas; pero el principio no alcanzaría a la arquitectura teatral, porque las variables que intervienen en la realización del espacio escénico son, como se explicó, móviles, múltiples y difíciles de conciliar.

También Fabrizio Milizia, autor del célebre Tratado completo, formal y material del teatro (1676), dejó constancia de lo que consideró la mayor virtud del Olímpico: al describir y proyectar las salas estables con tribunas y balcones, afirmó que por causa de esa disposición del auditorio, todas carecen de forma interior y son irregulares e incómodas; contrapuso como ejemplo de una gradería ideal «solamente la del teatro Olímpico, con el cual el vitruviano Palladio embelleció su patria vicentina». ${ }^{32}$ Casi un siglo después, en 1739,

31. «E se bene il fare, che tale unione fra il finto e il vero apparisca da tutti i luoghi, è cosa del tutto impossibile, nondimeno si può mediante l'arte situare talmente il detto punto, che pos- to l'occhio in una linea data, il finto apparisca unito col vero". La prattica di prospettiva, Venezia, 1596, en Ricci (1971: 88).

32. Milizia (1997: 77). 


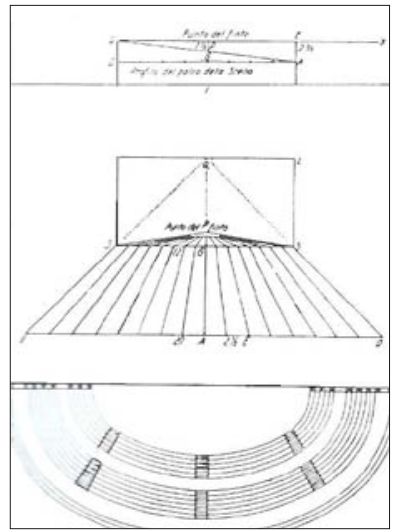

Figura 17

Lorenzo Sirigati, Esquema de la perspectiva aplicada al escenario, La pratica di prospettiva, Venezia, 1596.

Charles de Brosses describió la cávea de Palladio de la siguiente manera: «La forma de este teatro aventaja a la nuestra porque cada espectador, gracias a la disposición circular, está cerca de los actores, y porque en vista de que la voz siempre va hacia arriba, desde cualquier lugar se escucha igualmente bien». Al confrontar los teatros a la italiana con los que imitan el modelo vitruviano, critica de los primeros la dificultad de los espectadores de la platea para observar el espectáculo, pues tienen que mirarlo desde abajo hacia arriba. ${ }^{33}$

De entre las ventajas remarcables de la estructura del Teatro Olímpico hay, al menos, tres fundamentales: una cávea semielíptica elevada sobre el proscenio pero muy cercana a él, una planta homogénea que supera las irregularidades del contorno del terreno mediante elementos arquitectónicos como columnas y falsas fachadas, una escenografía con múltiples puntos de observación para privilegiar a un mayor número de observadores. La síntesis de estas características evidencia criterios de mayor relevancia e interés, como lo son la profunda jerarquización de las partes del teatro y la cuidadosa ponderación de los requerimientos para la representación y la buena observación de la audiencia.

Aunque el Olímpico fue inaugurado el último día del Carnaval, el hecho de que su construcción fuera motivada por la necesidad de un teatro y escenario de perpetua conservación para la realización de espectáculos públicos, habla de un momento de inflexión en la cultura teatral quinientista: la puesta en escena ya no resistía las improvisadas estructuras ni requería motivaciones

33. De Brosses (1992: 101-104). 
circunstanciales, como la fiesta, para alcanzar su realización. La representación de espectáculos como suceso autónomo y no ligado a la celebración de actos extraordinarios, y la construcción de edificios especialmente destinados al teatro, son dos consecuencias que dejan ver su implicación e importancia en la práctica teatral moderna. 


\section{Bibliografía}

Alberti, Leon Battista, Leonis Baptiste Alberti de re aedificatoria, Florentiae, impressum opera Magistri Nicolai Laurentii Alamani, 1485.

Attolini, Giovanni, «I luoghi teatrali e il teatro», Teatro e spettacolo nel Rinascimento, Bari, La Terza, 2000.

-, Teatro e spettacolo nel Rinascimento, Bari, La Terza, 2000.

Beltrami, Carlo, «Il Cinquecento. La nascita del teatro moderno», L'attore di carta. Storia della manualistica dell'attore, 1997-1998, 24-10-2007,<http://www. tesionline.it/default/tesi.asp?idt=11126>

Benevolo, Lonardo, Historia de la arquitectura en el Renacimiento, 2 Vol., Taurus, Madrid, 1973.

Carpeggiani, Paolo, "Teatri e apparati scenici alla corte dei Gonzaga, tra Cinque e Seicento", Bollettino del Centro Internazionale di Studi Architettonici, 1975 (17)101-118.

Craig, Edward A., "Introduzione, note e piante di teatri», Trattato sopra la struttura de' Teatri e Scene, Il Polifilo, Milano, 1972.

Cruciani, Fabrizio, Lo spazio del teatro, La Terza, Bari, 1992/2003.

De Brosses, Charles, Viaggio in Italia. Lettere familiari, Laterza, Roma-Bari, 1992.

Gallo, Alberto, La Prima rappresentazione al Teatro Olimpico. Con i progetti e le relazioni dei contemporanei, Il Polifilo, Milano, 1973.

González Román, Carmen, «El teatro y las visones fantásticas y arqueológicas de la antigüedad»; "El desarrollo del escenario en perspectiva», Spectacula. Teoría, arte y escena en la Europa del Renacimiento, Málaga, Universidad de Málaga, 2001.

Giustiniani, Orsatto, Edipo tiranno. con la lettera di Filippo Pigafetta che descrive la rappresentazione dell'Edipo re di sofocle al teatro Olimpico di Vicenza del 1585. Edición de Flavio Fiorese, Vicenza, Neri Pozza, 1984

Ingegneri, Angelo, Della poesia rappresentativa \& del modo di rappresentare le favole scenichel Discorso di Angelo Ingegneri al Serenissimo Signorel il Signor Don Cesare D'Estel duca di Modena \& di Reggio/ in Ferraral per Vittorio Baldini Stampatore Cameralel MDXCVIII/ con licenza di superiori et con privilegil

Ingegneri, Angelo, Della poesia rappresentativa e del modo di rappresentare le favole sceniche, Maria Luisa Doglio, Panini, Modena, 1989.

MacEwen, Indra Kagis, Vitruvios: writing the body of architetcure, Massachusetts, Cambrige, 2003.

Magagnato, Licisco, Teatri Italiani del Cinquecento, Neri Pozza, Venezia, 1954.

Mancini, Franco, Illusione e pratica teatrale: proposte per una lettura dello spazio scenico dagli Intermedi fiorentini all'Opera comica veneziana, Catalogo della mostra, Franco Mancini, Maria Teresa Muraro, Elena Povoledo, Vicenza, Neri Pozza, 1975. 
MacGregor, Jennifer, "Lighting of the Baroque theatres», 12-08-2008, $<$ http://www.geocities.com/jen_macgregor/SpecialTopicsPaper>

Marotti, Ferrucio, Lo spazio Scenico. Teorie e tecniche scenografiche in Italia (dall'età barocca al setecento), Roma,g Bulzoni, 1974.

Mazzoni, Stefano, L'Olimpico di Vicenza: un teatro e la sua "perpetua memoria», Firenze, Le Lettere, 1998

Mazzucato, Tiziana, "Teoría de la puesta en escena y de la representación teatral (1545-1630)", Teoría y Teatro. La teoría dramática del Renacimiento a la Posmodernidad, M. J. Vega ed., Mirabel, Pontevedra, 2004.

Milizia, Francesco, Trattato completo, materiale e formale del teatro, Forni, Bologna, 1997.

Molinari, Cesare, "Il teatro nella tradizione vitruviana: da Leon Battista Alberti a Daniele Barbaro", Biblioteca teatrale, 1 (1971) 30-46.

-, "Les rapports entre la scène et les spectateurs dans le théâtre italien du XVI siècle», Éditions du centre national de la recherche scientifique, Paris, 1986, (VII) 61-71.

Motta Carini, Fabrizio, Trattato sopra la struttura de' Teatri e Scene; Introducción de Edward A. Craig, Il Polifilo, Milán, 1972.

MotTa CARINI, Fabrizio, Trattato sopra la struttura de Theatri e scene. Che a nostri giorni si costumavano, e delle regole per far quelli con proportione secondo l'insegnamento della pratica maestra commune. Di Fabricio Carini Motta, architetto del serenissimo di Mantova, Consacrato al merito sublime dell'altezza serenissima Isabella Clara, arciduchessa d'Austria, duchessa di Mantova. In Guastalla, Per Alessandro Giauazzi Stampator Ducale. Con Licenza de'Superiori, 1676.

Nicoll, Allardyce, The Development of the theatre. A study of theatrical Art from the beginnings to the present day, George G. Harrap ed., London, 1927.

-, Lo Spazio Scenico, Storia dell'Arte Teatrale, Clelia Falletti traduttrice, Roma, Bulzoni, 1966/1971.

Pellegrino Prisciani, Spectacula, Danilo Aguzzi Barbagli, Franco Cosimo Panini ed., Panini: Modena, 1992.

Pallen, Thomas A., "Theatrical Scenery», Vasari on Theatre, Southern Illinois University Press, 1999.

Perrelli, Franco, Storia della scenografia. Dall'antichità al Novecento, Carocci, Roma, 2002.

PIERI, Marzia, La nascita del teatro moderno in Italia, tra xve xvi secolo, Torino, Bollati Boringhieri, 1989.

Pinelli, Antonio, I teatri. Lo spazzio dello spettacolo. Dal teatro umanistico al teatro dell'opera, Firenze: Sansoni, 1973.

Puppi, Lionello, Breve storia del Teatro Olimpico, Neri Pozza, Venecia, 1963.

- La rappresentazione inaugurale dell'Olimpico. Appunti per la restituzione di uno spettacolo rinascimentales, Critica d'Arte, IX/2 (1962)57-63 y IX/3 (1962) 57-69.

—, Andrea Palladio. Opera Completa. Mondadori Electa, Milano, 1977. 
Quagliarini, Enrico: Costruzioni in legno nei teatri allitaliana del 700 e 800. Il patrimonio nascosto dell'architettura teatrale marchigiana. Alinea Editrice, Firenze, 2008.

-, "La costruzione dei palchetti», in Costruzioni in legno nei teatri all'italiana del 700 e 800. Il patrimonio nascosto dell'architettura teatrale marchigiana. Alinea Editrice, Firenze, 2008, pp. 51-59.

-, "I palchetti in legno e la forma della sala», in Costruzioni in legno nei teatri all'italiana del 700 e 800. Il patrimonio nascosto dell'architettura teatrale marchigiana. Alinea Editrice, Firenze, 2008, pp. 67-74.

SAmbricio, Carlos, "La fortuna de Sebastiano Serlio», en Todas las obras de arquitectura y perspectiva de Sebastiano Serlo de Bolonia, Estudio lingüístico Fausto Díaz Padilla, Colegio Oficial de Aparejadores y Arquitectos Técnicos de Asturias, Oviedo, 1986.

Serlio, Sebastiano, Sebastiani Serlii Bononiensis de Architectura libri quinque, quibus cuncta fere Architectonica facultatis mysteria docte, perspicue, uberrimeque explicantur, a Ioanne Carolo Saraceno ex Italica in Latinam linguam nunc primum translati atque conversi, Venetiis, apud Franciscum de Franciscis Senesem \& Johannem Chriegher, 1569.

Schrade, Leo, La représentation d'Edipo tiranno au teatro Olimpico (Vicence 1585). Étude suive d'une édition critique de la tragédie de Sophocle par Orsatto Giustiniani et de la musique des choeurs par Andrea Gabrieli, CNRS Editions, Paris, 1960.

TAFURI, Manfredo, «Il luogo teatrale», Il teatro italiano nel Rinascimento, Fabrizio Cruciani e Daniele Seragnoli, Bologna, Il Mulino, 1987.

Tessari, Roberto, «Il teatro a Mantova tra 1563 e 1630: una mirabile galleria dell'effimero", 28-5-2005, <http://www.capitalespettacolo.it/ita/Tessari.asp>.

Vega Ramos, María José, La formación de la teoría de la comedia de Francesco Robortello, Universidad de Extremadura, Extremadura, 1987.

Ventrone, Paola: La scena prospettica rinascimentale: genesi e sviluppo, 21-022009, <http://74.125.47.132/search?q=cache:aBho7XBKlpIJ:e-prints.unifi. it/archive/00000491/01/03-Ventrone-la_scena.pdf+cortile+casa+cornaro\& $\mathrm{hl}=\mathrm{es} \& \mathrm{ct}=\mathrm{clnk} \& \mathrm{~cd}=8 \& \mathrm{gl}=\mathrm{es}>$

Vitruvio, De architectura. On architecture, F. Granger, ed., Cambridge, Mass. \& London, 1972.

Vitruvio, Gulielmi Philandri Castilionii Galli Civis Ro. in decem libros M. Vitruviis Pollionis de architectura annotationes, impressum Romae, apud Io. Andream Dossena Taurinen. 1544.

VItruvio, M. Vitruvius per iocundissimo solito castigatior factus cum figuris et tabula ut iam legi et intellegi possit [con epístola dedicatoria de Ioannes locundus HSC]. [Colophon: Impressum Venetiis ac magis q. unquam aliquo alio tempore emendatum: sumptu miraque diligentia Ioannes de Tridino alias Tacuino, 1511]

Vitruvio, M. Vitruvius Pollionis de Architectura Libri decem ad Caesarem Augustum, omnibus editionibus longe emendatiores, collatis veteribus exemplis. Accesse- 
runt Gulielmi Philandri Castilionii, civis Romani annotationes, castigationes \& plus tertia parte locupletiores. Adiecta est Epitome in omnes Georgii Agricolae de mensuris \& ponderibus libros, Lugduni, Apud Ioan Tornaesium, 1552.

WitTKower, Rudolf, "Brunelleschi y la 'proporción en perspectiva», Los fundamentos de arquitectura en la Edad del Humanismo, Alianza, Madrid, 1995.

ZorzI, G., "Le prospettive del teatro Olimpico di Vicenza nei disegni degli Uffizi di Firenze e nei documenti dell'Ambrosiana di Milano", Arte Lombarda X/2 (1965)89-94.

ZorzI, Ludovico: "Tra Ruzzante e Vitruvio. Appunti sul luogo scenico di Casa Cornaro", Alvise Cornaro e il suo tempo, a cura di L. Puppi, Catalogo della mostra, Padova, Comune di Padova, 1980.

—, Il teatro e la città, Einaudi, Torino, 1977.

—, "Elementi per la visualizazzione della scena veneta prima del Palladio», Studi sul teatro veneto fra Rinascimento ed Età Barocca, Firenze, 1971.

-, "Il teatro Olimpico nel suo splendore», Atti dell'Academia Olimpica, II (1909-1910) 7-37.

Zorzi, Ludovico; Innamorati, Giuliano; Ferrone, Siro: Il teatro del Cinquecento, Sansoni, Firenze, 1982. 